Passagens. Revista Internacional de História Política e Cultura Jurídica, Rio de Janeiro: vol. 3 no.1, janeiro-abril 2011, p. 77- 98.

\title{
A FOICE FACE AO TANQUE: ORGANIZAÇÕES DE TRABALHADORES RURAIS FRENTE AOS REGIMES MILITARES NO BRASIL E NO PERU (1961-1988)
}

\section{LA HOZ FRENTE AL TANQUE: ORGANIZACIONES DE TRABAJADORES RURALES FRENTE A LOS REGÍMENES MILITARES EN BRASIL Y PERÚ (1961-1988)}
THE SICKLE FACES THE TANK: RURAL WORKERS ORGANIZATIONS CONFRONT MILITARY REGIMES IN BRAZIL AND PERU (1961-1988)

\section{LA FAUCILLE FACE AU TANK : ORGANISATIONS DE TRAVAILLEURS RURAUX FACE AUX RÉGIMES MILITAIRES AU BRÉSIL ET AU PÉROU (1961-1988)}

\section{DOI: $\underline{10.5533 / 1984-2503-20113104}$}

\section{Vanderlei Vazelesk Ribeiro}

\section{RESUMO}

Neste trabalho discutimos a atuação dos movimentos camponeses brasileiros e peruanos ante os respectivos regimes militares. Para tanto concentramo-nos na atuação de entidades como a Confederação Nacional dos Trabalhadores na Agricultura (Contag) criada pouco antes do golpe militar de 1964 - e da Confederación Campesina del Perú, que já tinha um trabalho expressivo antes da tomada do poder pelos militares em 1968. Inicialmente, analisamos as conjunturas anteriores aos respectivos golpes militares, chamando a atenção para as mobilizações de camponeses e o temor que despertaram entre lideranças das forças armadas. Esse temor levou-as não apenas a repressão, mas também a buscar saídas para cooptar os movimentos camponeses. Posteriormente refletimos a respeito da interação entre as entidades estudadas e as burocracias civis e militares durante os períodos ditatoriais. Aqui cotejamos o legalismo da entidade brasileira e as mudanças de perspectivas de sua homóloga peruana, que após séria crise veria parte de seus líderes aceitarem a reforma agrária efetivada pelo general-presidente Velasco Alvarado. Enquanto isso, no Brasil, não se aplicava a reforma agrária, agora prevista em lei, mas a mesma continuava como bandeira nas mãos da Contag. Finalmente pensamos o papel das entidades nas conjunturas de transição e da grave crise econômica e política da década de 1980. Trabalhamos metodologicamente com a análise histórico-social comparada.

Palavras-chave: Movimentos camponeses, regimes militares, Brasil e Peru. 


\section{RESUMEN}

En este trabajo discutimos la actuación de los movimientos campesinos brasileños y peruanos ante los respectivos regímenes militares. Para eso nos concentramos en la actuación de entidades como la Confederación Nacional de los Trabajadores en la Agricultura (Contag) - creada poco antes del golpe militar de 1964 - y de la Confederación Campesina del Perú, que ya tenía un expresivo trabajo antes de la toma del poder por los militares em 1968. Inicialmente analizamos las coyunturas anteriores a los respectivos golpes militares, llamando la atención para las movilizaciones de campesinos y el temor que despertaron entre liderazgos de las fuerzas armadas. Esse temor los llevó no sólo a la represión, pero también a buscar salidas para cooptar a los movimientos campesinos. Posteriormente refletimos sobre la interacción entre las entidades estudiadas y las burocracias civil-militares durante los periodos dictatoriales. Aquí cotejamos el legalismo de la entidad brasileña y los cambios de perspectivas de su homóloga peruana, que tras seria crisis política vería parte de sus liderazgos aceptaren la reforma agraria realizada por el general-presidente Velasco Alvarado. Mientras eso, en Brasil no se aplicaba la reforma agraria, ahora prevista por ley, pero ella seguía como bandera en las manos de la Contag. Finalmente pensamos el papel de las entidades en las coyunturas de transición y de la grave crisis económica y política de la década de 1980. Trabajamos metodologicamente con el análisis histórico-social comparado.

Palabras-clave: Movimientos campesinos, regímenes militares, Brasil y Perú.

\section{ABSTRACT}

In this text we discuss the activities of the Brazilian and Peruvian farmworkers movements with respect to the respective military regimes of the two countries. Specifically, we focus on the activities of entities such as the Confederação Nacional dos Trabalhadores na Agricultura (National Confederation of Agricultural Workers) - Contag- (created shortly before the military coup of 1964) and of the Confederación Campesina del Perú (Farmworkers Confederation of Peru), which already had an expressed purpose before the military took over in 1968 . We begin by analyzing the situation prior to the respective military coups, calling attention to the mobilizations of the farmworkers and the fear that this awakened in the leaders of the armed forces. This fear drove these leaders not just to exercise repression, but also to seek to co-opt the farmworkers movements. We then reflect on the interaction between the entities being studied and the civil-military bureaucracies during the dictatorial periods. Here, we tell about the legalization of the Brazilian movement and the changes in perspectives of its Peruvian counterpart, which 
would later see some of its leaders accept the agrarian reform instituted by GeneralPresident Valasco Alvarado. In respect to this, the agrarian reform that had just been written into Brazilian law was never put into practice in Brazil, but it continued as a rallying cry in the hands of the Contag. Finally, we consider the role of the entities in the transitional situations and of the grave economic and political crisis of the 1980's. We proceed methodologically with a comparative socio-historical analysis.

Key words: Farmworkers movements, military regimes, Brazil and Peru.

\section{RÉSUMÉ}

Dans cet article, nous discuterons l'action des mouvements paysans brésiliens et péruviens face aux régimes militaires des deux pays. À cette fin, nous nous concentrerons sur des organisations telles que la Confédération nationale des travailleurs agricoles CONTAG - (créée peu avant le coup d'État militaire de 1964) et la Confederación Campesina del Perú (Confédération paysanne du Pérou), qui avait déjà fait un travail significatif avant la prise de pouvoir par les militaires en 1968. Nous analyserons d'abord les conjonctures antérieures aux coups d'État respectifs, en insistant sur les mobilisations des paysans et la crainte que ceux-ci inspirèrent parmi les chefs des forces armées. Cette crainte amena non seulement à la répression, mais aussi à la recherche de moyens de coopter les mouvements paysans. Nous porterons ensuite notre réflexion sur les interactions entre les organisations en question et les bureaucraties civilo-militaires durant les périodes dictatoriales. Nous comparerons le légalisme de l'organisation brésilienne et les changements de perspectives de son homologue péruvienne, qui après une série de crise verra ses dirigeants accepter la réforme agraire mise en oeuvre par le Généralprésident Velasco Alvarado. Pendant ce temps-là, au Brésil, aucune réforme agraire n'était à l'oeuvre (alors qu'elle est aujourd'hui prévue par la loi), et elle demeurait l'étendard de la Contag. Finalement, nous réfléchirons au rôle de ces organisations dans les conjonctures de transition et de grave crise économique et politique des années 1980. Nous userons ici de la méthode d'analyse historico-sociale comparée.

Mots-clés : mouvements paysans, régimes militaires, Brésil, Pérou.

Em 1961 reuniu-se em Belo Horizonte o primeiro Congresso de Lavradores e Trabalhadores Agrícolas do Brasil convocado pela União dos Lavradores e Trabalhadores Agrícolas do Brasil (Ultab) e que ficaria conhecido como Primeiro Congresso Camponês do Brasil. Inicialmente, as propostas da direção da Ultab tendiam mais a sustentar a 
necessidade de medidas como a extensão dos direitos trabalhistas ao campo e a defesa dos posseiros e arrendatários, dentro do que preconizava a direção do Partido Comunista Brasileiro. Contudo o discurso de Francisco Julião, que clamava por uma reforma agrária "[...] na lei ou na Marra!, com Flores ou com Sangue", galvanizou o encontro. A tese da reforma agrária radical ganhou a atenção do congresso e acabaria sendo vitoriosa ${ }^{1}$.

Naquele mesmo ano, uma greve geral de yanaconas ${ }^{2}$ agitava a Serra Peruana, ao mesmo tempo em que as ocupações de terra se intensificavam. No ano seguinte, as ocupações ganharam maior impulso sob o impacto da atuação de Hugo Blanco, o líder trotskista que organizava as ações e criava seu próprio decreto de reforma agrária ${ }^{3}$.

Escolhemos estes dois momentos para iniciar este trabalho porque marcaram pontos de radicalização de posições no que dizia respeito à questão agrária em ambos os países. No caso brasileiro o discurso de Julião ganhou a simpatia de amplos setores da esquerda, mas também atraiu a atenção dos setores proprietários, que logo passaram a articular-se em torno do Instituto de Pesquisas e Estudos Sociais (Ipês), que buscaria, num primeiro momento, barrar a mobilização em favor de reformas sociais e, depois, implantar sua própria versão modernizadora ${ }^{4}$. No caso peruano, a reação militar às ocupações de 1962 combinaria repressão e esforços de cooptar lideranças, crescendo a noção da imperiosidade de uma reforma agrária ${ }^{5}$.

Comparar é um trabalho tão difícil quanto necessário. Ainda mais quando cotejamos duas sociedades a um tempo vizinhas e desconhecidas, como a brasileira, fortemente urbanizada e industrializada, num processo que decolou a partir da Revolução de 1930; e a peruana, que embora seja hoje mais urbanizada, tem uma industrialização muito mais restrita. Neste trabalho, avaliaremos a atuação de duas entidades que nos permitem perceber como os movimentos de trabalhadores rurais enfrentaram as condições estabelecidas a partir da instalação de regimes militares, que, tendo perfis bastante distintos, fizeram da bandeira de reforma agrária (mais ao nível discursivo, no Brasil, e na prática de seu governo, no Peru) um meio para modernizar seus países.

Analisaremos a caminhada da Confederação Nacional dos Trabalhadores na Agricultura (Contag), no Brasil, e da Confederación Campesina del Perú (CCP),

\footnotetext{
${ }^{1}$ Ver: Medeiros, Leonilde Sérvulo (1989). História dos Movimentos Sociais no Campo, Rio de Janeiro: Fase, p. 45.

${ }^{2}$ Yanaconas era o trabalhador que vivia sob dependência do patrão tendo de prestar-Ihe uma infinidade de serviços gratuitos.

${ }^{3}$ Mar, José Matos; Mejía, José Manuel (1980). La Reforma Agraria en el Peru, Lima: Instituto de Estudios Peruanos, p. 69.

${ }^{4}$ Ver: Dreifus, René Armand (1964). A Conquista do Estado, Petrópolis: Vozes.

${ }^{5}$ Ver: Medrano, Eduardo Toche (2008). Guerra y Democracia: Los Militares Peruanos y La Construción Nacional, Lima: Desço-clacso, p. 145.
} 
procurando identificar como dialogaram com os regimes militares implantados em seus países. Inicialmente, discutimos a situação nos períodos anteriores aos golpes militares, que foram marcadas, especialmente no caso brasileiro, por uma importante mobilização de trabalhadores rurais e, no caso peruano, por uma "memória" militar a respeito do que ocorrera poucos anos antes.

Posteriormente, avalia-se a atuação dos rurícolas face aos regimes ditatoriais: como a Contag buscou fazer valer o Estatuto da Terra decretado poucos meses após a vitória do movimento militar e como a CCP dialogou com a reforma agrária em marcha no Peru. Finalmente, reflete-se a respeito da atuação das duas entidades nas conjunturas de transição e gravíssima crise política e econômica que marcaram ambos países na década de 1980.

Certamente, este trabalho é apenas uma aproximação ao tema e o leitor deve estar preparado mais para um vôo panorâmico do que para uma análise mais aprofundada. Contudo, é um primeiro olhar certamente precário, mas necessário, sobre a experiência destes movimentos rurais em ambas as sociedades.

\section{EMERGÊNCIA CAMPONESA}

Tomemos a década de 1950 como marco para este estudo. Nos dois países, as cidades cresciam, com o Brasil marcado pelo processo de industrialização, e o Peru, pelo crescimento do setor de serviços. A agricultura era percebida por economistas e intelectuais de outras áreas como um gargalo, que estrangulava o desenvolvimento, pois não produzia alimentos para as cidades em nível suficiente e não gerava o amplo mercado interno para a indústria, que crescia no Brasil e apenas engatinhava no país do Pacífico. Por outro lado as revoltas rurais começavam a ser percebidas por setores dos dois exércitos como potencialmente rúpteis. No Brasil, a tradição de enfrentamento entre exército e rebeldes camponeses remontava a Canudos ${ }^{6}$, mas, num contexto de guerra fria, os protestos rurais ganhavam outra dimensão. Ainda mais que o Partido Comunista do Brasil (PCB) ${ }^{7}$ buscara fazer do conflito armado de Porecatu (1948-1951), no Paraná, o foco inicial da revolução brasileira, bem como participara ativamente na defesa de

\footnotetext{
${ }^{6}$ Revolta de ampla magnitude no sertão da Bahia, onde, sob inspiração de um líder messiânico e religioso, conhecido por Antonio Conselheiro, milhares de sertanejos resistiram a forças estaduais e federais para defender o seu Arraial de Canudos. Sobre a luta de Canudos ver, por exemplo: Moura, Clovis (1983). Sociologia Política da Guerra de Canudos, SP: Hucitec.

${ }^{7}$ Em 1962 houve uma cisão nas fileiras comunistas. O PCB ficaria sendo o Partido Comunista Brasileiro e o PCdoB seria o Partido Comunista do Brasil.
} 
posseiros que se rebelaram contra a sua expulsão da região de Trombas e Formoso, no norte de Goiás, a partir de $1955^{8}$.

Também no Peru não eram novidade os enfrentamentos. Um Relatório ao III Congresso da Confederación Campesina del Perú descrevia os inumeráveis levantes de comunidades indígenas, que remontavam aos fins do século XIX, contra os gamonales (o equivalente peruano do coronel brasileiro), que se intensificariam no país a partir da década de $1920 .^{9}$ A atenção militar dividia-se entre a atuação dos comunistas, que influenciavam o trabalho da CCP e as ações da Aliança Popular Revolucionária Americana (Apra), que desde os anos 1930 buscava sindicalizar os trabalhadores na costa açucareira.

Tanto os militares peruanos como os brasileiros percebiam o meio agrário como o foco de onde poderia vir a insurreição, que desencadearia a temida revolução comunista. O general brasileiro Octávio Costa lembrava que a formação francesa que ainda ecoava nos oficiais brasileiros mostrava-Ihes como os franceses foram derrotados na Argélia, aprendiam também o que os portugueses estavam vivenciando em Angola e, principalmente, o exemplo da Revolução Cubana, de onde Fidel Castro recrutara os camponeses como base de seu exército rebelde ${ }^{10}$.

A atuação do Partido Comunista nos respectivos meios agrários remontava à década de 1940. No Brasil, as primeiras ligas camponesas organizaram-se no Rio de Janeiro, Pernambuco e São Paulo, no curto período de legalidade do partido, entre 1945 e 1947. Após o fracasso da experiência de Porecatu, o partido volta-se para o esforço de construir sindicatos legais e realiza a primeira conferência de trabalhadores rurais em 1953. A Ultab foi criada na segunda conferência, em 1954. No caso peruano, a presença comunista faz-se sentir na criação da CCP, em 1947, ao lado de socialistas e apristas ${ }^{11}$.

\footnotetext{
${ }^{8}$ Ver: Martins, José de Souza (1984). A Militarização da Questão Agrária, Petrópolis: Vozes. p. 35-47.

${ }^{9}$ Os confrontos entre comunidades e fazendas, onde estas arrebatavam aquelas a suas áreas, remontavam aos fins do século XIX. Tanto na costa como na serra, fazendeiros ligados à produção de açúcar ou de gado buscavam expulsar as comunidades a fim de expandirem seus latifúndios. Ver: Colombo, Silvia; Soares, Gabriela Pelegrino (1999). Reforma Liberal e Lutas Camponesas na América Latina: Peru e México nas últimas décadas do século XIX e princípios do século $X X$, SP: Humanitas, p. 35.Ver também: Informe Central AL - III Congreso de La Confederación Campesina del Peru In: Jornal Voz Campesina, CCP, Março de 1972, no. 1 , p. $4-7$.

${ }^{10}$ Ver: Castro, Celso (1995). Visões do Golpe Memória Militar sobre 1964, Rio de Janeiro: Fundação Getúlio Vargas [V.I], p. 137.

${ }_{11}^{11}$ Ver: Salgado, Carlos Monge (1989). Agremiación en el Campo Peruano: La Historia de la Confederación Campesina, Lima: Latino-American Studies Association, p. 14. Ao analisarmos memórias produzidas por dirigentes da CCP podemos perceber as mudanças a respeito das origens da entidade. No citado informe de 1970, a participação dos comunistas em sua organização é exaltada num tempo em que a facção maoísta liderada por Saturnino Paredes, inspirada no grupo Bandera Roja, estava à frente da entidade. Hoje, quando me entrevistei com Jorge Prado, secretário-geral da entidade, tanto a presença comunista
} 
No Brasil, se a Ultab, controlada pelo PCB, sofreu uma relativa paralisia após a crise suscitada pelo $20^{\circ}$ Congresso do PCUS, o ano de 1955 marcaria o renascimento das ligas camponesas. No Rio de Janeiro, crescem movimentos de luta pela terra na Baixada Fluminense. No Rio Grande do Sul, em 1960, nasce o Movimento dos Agricultores sem Terra (Máster), apoiado pela ala do Partido Trabalhista Brasileiro (PTB) liderada pelo então governador do estado, Leonel Brizola. Preocupada com o avanço da esquerda no meio agrário, a Igreja Católica começa a estimular o crescimento de sindicatos rurais e a criar organizações como as Frentes Agrárias Gaúcha, Paranaense e Paraense $^{12}$. Vale salientar que uma parte da Igreja Católica passa a questionar mais vivamente o modelo capitalista de desenvolvimento e, através da Ação Popular (DÚVIDA: AQUI O AUTOR REFERE-SE À AP, O MOVIMENTO, OU A "AÇÃO POPULAR" COMO MÉTODO GENÉRICO DE ATUAÇÃO SOCIAL?), começar a atuar no meio agrário.

No caso peruano, as memórias produzidas por sindicalistas ligados à CCP não valorizam a presença da Igreja. O Informe Central citado sublinha o apoio prestado por padres ao setor latifundista. Contudo, destaca a presença católica na organização de sindicatos em regiões como Cajamarca, Puno e Cuzco.

O crescimento dos movimentos rurais possibilitou, como vimos, a realização do primeiro congresso camponês no Brasil e, a partir deles, intensificaram-se as lutas agrárias. No Nordeste, o discurso das ligas radicalizava-se ${ }^{13}$ com ênfase na possibilidade de uma revolução socialista vinda do campo, havendo ações de ocupações de terra e, principalmente, resistência à expulsão dos engenhos, como na célebre desapropriação de Galiléia, em Pernambuco. ${ }^{14}$

No mesmo estado, o PCB busca apoiar os assalariados arrancando, em aliança com as ligas, importantes concessões após a greve geral de 1963. No Rio Grande do Sul, floresciam os acampamentos exigindo a reforma agrária e, em São Paulo, greves para forçar o patrão a pagar os salários. Em julho de 1963, grupos mais ligados à ala conservadora da Igreja procuram criar a Confederação Nacional dos Trabalhadores na Agricultura (CNTA). Pressionado pelos grupos de esquerda, o governo João Goulart não reconhece a entidade e é convocado um novo encontro para o Rio de Janeiro. Em

quanto a aprista são escamoteadas, exaltando-se uma "autonomia" dos camponeses. Entrevista com o autor realizada em 16 de julho na sede da CCP, em Lima.

${ }^{12}$ Ver: Bassani, Paulo (2009). Frente Agrária Gaúcha e Sindicalismo de Trabalhadores Rurais, Londrina: EDUEL, p. 35.

${ }_{13}$ Ver: Ayved, Bernardete (1982). A Vitória dos Vencidos. Dissertação de Mestrado, UFPB, Campina Grande, p. 79.

${ }^{14} \mathrm{O}$ Engenho Galiléia foi o primeiro a ser desapropriado após uma luta de quatro anos, iniciada a partir da formação do que viria a ser a primeira das ligas camponesas lideradas pelo deputado estadual e advogado de camponeses Francisco Julião. 
dezembro de 1963, realiza-se, na antiga capital, a eleição da primeira diretoria chefiada por Lindolfo Silva, o experiente líder comunista. PCB e AP estavam melhor representados na agremiação, havendo menor representação para lgreja conservadora e mínima para as ligas. ${ }^{15}$

Toda essa movimentação, entretanto, enfrentaria a mobilização do setor proprietário, que aliado à ala mais conservadora da Igreja, apoiou o golpe civil-militar que derrubou o governo Goulart e desencadeou a repressão contra o emergente movimento sindical.

No Peru, o ano de 1962 seria extremamente importante não só para o movimento camponês como para todo o conjunto da sociedade. Em relação ao movimento, realizamse os congressos da CCP sob forte influxo da Bandera Roja e da Fencap, liderada por apristas $^{16}$. No mesmo ano, na província de La Convención, departamento de Cuzco, efetivam-se as já citadas ocupações de terras lideradas por Hugo Blanco, que seriam mais tarde chamadas "recuperações confiscatórias"17. A reação militar combinou repressão e concessões. Hugo Blanco e outros líderes foram presos e houve assassinatos, especialmente depois que ocorreu um golpe militar, que impediu a vitória eleitoral do histórico líder aprista Victor Raul Haya de La Torre.

Visto desde os anos 1930 como um comunista, por ter estimulado uma revolta de marinheiros em favor de sua candidatura presidencial derrotada em 1931 e novamente haver incitado um levante de marinheiros em 1948 para levá-lo ao poder, Haya de La Torre agora era percebido por setores militares, que uniam anticomunismo e nacionalismo, como um aliado do imperialismo norte-americano. Portanto, Haya de La Torre não faria as reformas que agora muitos no exército, liderados pelo general Edigardo Mercado Jarrin, imaginavam necessárias. Estes oficiais pensavam que o país precisava de desenvolvimento para ter a segurança.

Até aqui, nada distinto de seus homólogos brasileiros. Contudo, se, em nosso país, tratava-se de conter movimentos sociais e apoiar a industrialização, que já se desenvolvia desde os anos 1930, no Peru, seria o Estado, guiado pelas forças armadas, que faria 0 processo de substituição de importações. Por isso, a reforma agrária para os oficiais peruanos começava a ganhar um sentido de muito maior urgência. Daí o governo militar

\footnotetext{
${ }^{15}$ Ver: Medeiros, L. S. (1989). Op. cit., p. 62. Ver também: http://www.contag.org.br/imagens/CONTAGRevista40anos.pdf, p. 23.

${ }_{16}$ Ver: Salgado, C. M. (1989). Op. cit., p. 17. Enquanto a CCP apoiava as ocupações de terra nas zonas serranas, a Federación Campesina del Peru (Fencap), criada em 1958, dedicava-se a atuar na zona costeira apoiando greves do setor açucareiro. As duas entidades não coordenavam seus trabalhos.

${ }^{17} \mathrm{O}$ termo era usado, pois, na visão de muitos camponeses, tratava-se da comunidade retomar o que tinha perdido para a fazenda. Saliente-se, contudo, que nem sempre as terras ocupadas tinham pertencido às comunidades.
} 
de Pérez Godoy ter lançado as primeiras bases para uma reforma agrária. Com o apoio militar, Fernando Belaunde Terry, que perdera as eleições de 1962, venceu as do ano seguinte, e conseguiu aprovar num parlamento hesitante a lei de reforma agrária ${ }^{18}$.

Foi fácil para o exército peruano reprimir as guerrilhas do Movimiento de Izquierda Revolucionaria, em 1965, e, de passagem, continuar a prisão de dirigentes da CCP e da Fencap. Mas a noção de que uma reforma agrária radical devia ser feita ganhava corações e mentes. Nos quatro anos da lei aprovada sob Belaunde, apenas 14 mil famílias tinham sido assentadas, ganhando a reforma agrária um caráter de urgência, fosse para ampliar o mercado da indústria, fosse para prevenir conflitos. O golpe militar que expulsou Belaunde Terry do país não está imediatamente relacionado à questão agrária, vinculando-se a questões como a presença da International Petroleum Company no país, mas a rapidez com que medidas práticas foram tomadas em favor da reforma e sua efetiva realização demonstraram como o novo setor no poder sentia a necessidade de sua aplicação. ${ }^{19}$

Como a Contag e a CCP reagiram ante os novos quadros? Como os trabalhadores rurais brasileiros atuaram face um novo poder autoritário, que emergira exatamente contra suas bandeiras? Como os líderes da CCP viram suas bandeiras em mãos de um novo regime autoritário?

\section{A FOICE FACE AO TANQUE: OS MOVIMENTOS CAMPONESES FRENTE AOS GENERAIS}

No Brasil, a ação inicial do governo chefiado pelo Marechal Castello Branco foi marcada pela repressão. Líderes como Lindolfo Silva e Francisco Julião tiveram de partir para o exílio e a Contag sofreu intervenção, ficando sob a orientação de José Rota, ligado aos sindicatos católicos de São Paulo. Tavares ${ }^{20}$ mostra como, em Pernambuco, a Fetag livrou-se da intervenção com o apoio do padre Paulo Crespo, contra as arremetidas do padre Melo, mais conservador.

A entidade pernambucana e, mais tarde, a Contag contaram com o apoio do Instituto Americano para o Desenvolvimento do Sindicalismo Livre (IADSIL), que buscava

\footnotetext{
${ }^{18}$ Ver: Cotler, Julio (2006). Peru: Estado, Classe e Nação, Brasília, Fundação Alexandre Gusmão, p. 231245; Medrano, E. T. (2008). Op. cit., p. 135.

${ }_{19}$ Já é muito mais do que o Brasil fizera sob governo militar, quando 1.482 famílias foram assentadas. Ver: Silva, José Gomes da (1971). A Reforma Agrária no Brasil: Frustração Camponesa ou Instrumento de Desenvolvimento? Rio de Janeiro: Zahar, p. 135.

${ }^{20}$ Ver: Tavares, Ricardo (1992). Contag: da Ditadura à Transição. Memória Social e Construção Política do Campesinato. Dissertação de Mestrado, luperj, Rio de Janeiro.
} 
informar sobre legislação trabalhista, administração sindical, mas nunca sobre reforma agrária. A memória desse período é, aliás, escamoteada no discurso contagueano ${ }^{21}$. Jamais encontramos qualquer referência de alguma assistência estadunidense a sindicatos peruanos, mas o estado de nossa pesquisa não nos permite descartar essa hipótese.

Enquanto isso, no interior do aparelho de Estado, Castello Branco e seu ministro do Planejamento, Roberto Campos, entendiam que não bastava reprimir, mas era preciso cooptar. Assim, já em maio de 1964 criava-se um grupo de trabalho para discutir o Estatuto da Terra. Não cabe neste trabalho refletir sobre as idas e vindas do estatuto, bastando dizer que, em 30 de novembro, era publicado no Diário Oficial, após intensa batalha no Congresso Nacional e na imprensa. Pela primeira vez no Brasil se definia o que fosse latifúndio por não exploração ou por dimensão (600 vezes o módulo fiscal de uma dada região), permitia-se a desapropriação com pagamento em títulos da Dívida Agrária (pomo da discórdia durante o governo Goulart) e determinava-se a criação de cooperativas de reforma agrária.

Para Carmem Salis ${ }^{22}$, a dificuldade de se implantar o Estatuto da Terra estava não apenas nas resistências que enfrentava dentro e fora do governo, mas na própria lógica do projeto. Seria preciso fazer primeiro um gigantesco cadastro de terras (num país que jamais o fizera), depois estabelecer a partir de inúmeros critérios o que seria o módulo fiscal da região para só depois enfrentar o problema da desapropriação.

De todo modo, o estatuto serviria como uma bandeira para aglutinar novamente o movimento de trabalhadores. Agora a reforma agrária nada tinha de subversiva, pois estava na legislação. Em 1966, durante o 1 Congresso de Trabalhadores Rurais, a Contag confirma José Rota na presidência, mas, dois anos depois, chega à direção o grupo pernambucano de José Francisco da Silva, apoiado nas alas católicoconservadoras da Frente Agrária Gaúcha.

Ainda conforme Carmem Salis, a partir do governo Costa e Silva, o Estatuto da Terra, no que dizia respeito à questão da reforma agrária, vai sendo deixado de lado em favor de uma política agrícola mais favorável aos grandes proprietários de terra. Para o então ministro Delfim Neto, muito mais eficaz do que desapropriar terras e oferecer treinamento técnico para uma multidão de pequenos proprietários era qualificar os que já

\footnotetext{
${ }^{21}$ Ibidem, p. 45.

${ }^{22}$ Ver: Salis, Carmem Lucia Gomes de (2008). Estatuto da Terra: Origem e (Des)caminhos da Proposta de Reforma Agrária nos Governos Militares. Tese de Doutorado, Unesp, Assis, p. 195.
} 
possuíam terras. Para os sem-terra, uma miragem, aliás, muito antiga seria apresentada: a Amazônia, a ser ocupada com projetos de colonização. ${ }^{23}$

Com o endurecimento do regime militar, a partir de 1968, a repressão também se intensificaria sobre o sindicalismo rural. Contudo os dirigentes da Contag partiram para o legalismo, linha que tornou possível sua sobrevivência no período mais difícil do regime militar. Em sua revista $O$ Trabalhador Rural, os dirigentes da Contag mostram a reforma agrária como algo que está dentro da lei. A atuação legalista também se dava quando advogados esforçavam-se por tornar cara a indenização por benfeitorias para os proprietários, mantendo o posseiro o maior tempo possível na terra. Aliás, a primeira coisa que se procurava fazer, sempre que possível, era questionar justamente o título de propriedade apresentado pelo pretenso dono da terra ${ }^{24}$. Além disso, luta-se por cumprimento dos direitos trabalhistas no campo e, a partir de 1971, os sindicatos passaram a ser mediadores para que os trabalhadores do campo recebessem suas aposentadorias pelo Funrural.

Vale dizer que este "legalismo" da direção da Contag não significa falta de combatividade. Em uma das seções de O Trabalhador Rural, "Conversa de Caboclo", defendia-se o usucapião e a necessidade de o trabalhador rural se sindicalizar. Mais ainda: no texto mostra-se o momento em que é feita a reunião, rejeitando-se educadamente, é claro, a proposta de um vereador de controlar o sindicato. ${ }^{25}$ Procuravase explorar as brechas da legislação. A Fetag do Rio Grande do Sul, por exemplo, solicitava ao governo Costa e Silva, que implementasse o Ato Institucional número 9, que determinava que a indenização não fosse mais prévia, além do Decreto-lei 582, de maio de 1969, que determinava a desapropriação da terra em rito sumário. ${ }^{26}$ Desta forma, embora continuassem ocorrendo as expulsões de posseiros e o êxodo rural se intensificasse, a Contag ia, bem ou mal, constituindo-se numa referência para os trabalhadores do campo e para os movimentos de oposição pacífica ao regime militar.

A situação no Peru seria bastante distinta. No Brasil, a reforma agrária fazia parte do ideário de um setor intra-aparelho, mas, a partir de 1967, ia tornando-se cada vez mais

\footnotetext{
${ }^{23}$ Saliente-se que o discurso a respeito do "mar Amazônico", com imensos "vazios demográficos", já era utilizado durante o Estado Novo, quando se agregou a noção de "marcha para o oeste" à ideia da Amazônia a conquistar. Ver, por exemplo, Lenharo, Alcir (1986). Trabalho e Colonização no Brasil: Nordeste, Amazônia, Centro-oeste, Campinas: Papirus, p. 21. Ver também: Ribeiro, Vanderlei Vazelesk (2008). Cuestiones Agrarias en el Varguismo y el Peronismo, Quilmes, Universidad Nacional de Quilmes, p. 125.

${ }^{24}$ Ver: Barcelos, Fernando (2008). Sindicalismo e Luta pela Terra no Rio de Janeiro. Dissertação de Mestrado, Centro de Pós-Graduação em Desenvolvimento Agrário, Rio de Janeiro, p. 131.

${ }^{25}$ Ver "Conversa de Caboclo". In: Revista o Trabalhador Rural. Rio de Janeiro, Contag, Setembro de 1969, Ano 1, No. II, p. 23.

${ }^{26}$ O Ato Institucional número 9 fora decretado durante a disputa no interior do governo. O ministro do Interior, general Albuquerque Lima, que mais tarde lutaria com Médici pela indicação para Presidência da República, defendia a realização de uma reforma agrária. Ver: Silva, J. G. (1971). Op. cit, p. 145.
} 
minoritária. Aqui prevalecia a ideia da modernização via tecnologia. No caso peruano, para os "coronéis de esquerda", que hegemonizavam o processo, a reforma agrária não servia apenas para conter os conflitos, mas sim para criar mercado para uma indústria, que iria precisar muito mais do Estado que a brasileira. Foram necessários seis dias para que se expropriasse a petroleira International Petroleum Company, com tanques de guerra cercando suas instalações. Poucos meses depois, os tanques de guerra cumpriram outra missão: expropriar o Engenho Casa Grande, símbolo da oligarquia açucareira.

No Brasil, as entidades de proprietários rurais tinham sido decisivas no apoio ao golpe e o campo ainda era o principal motor das exportações. No Peru, a situação era diametralmente oposta: os setores proprietários assistiram em casa ao golpe, e ali as minas, que também se nacionalizavam, eram desde tempos coloniais a principal fonte de riqueza. Provavelmente daí resulte a incapacidade do setor proprietário em conter a reforma agrária. O Decreto-lei 17.716 de 24 de junho (Dia do Índio) estabeleceu uma área máxima a partir da qual as terras poderiam ser desapropriadas: 150 hectares na costa e um pouco menos na serra. A selva amazônica era pensada para a colonização. As novas áreas seriam cooperativizadas e passariam ao controle estatal. Os camponeses pagariam pela terra após cinco anos.

De todo modo, as desapropriações começaram: os fazendeiros recebiam indenizações, mas eram pagas de forma lenta ${ }^{27}$. As cooperativas se organizavam a partir da intervenção estatal com nomeações de técnicos pelo governo e em alguns casos oficiais do exército eram seus interventores. Bem ou mal a reforma Agrária ia-se desenvolvendo, embora os problemas não tardassem a se manifestar.

Qual a reação dos dirigentes da Confederación Campesina? Como vimos, desde o início dos anos 1960 a direção da CCP era influenciada pelo maoísmo. Tal influência era tão vigorosa que havia dirigentes que só aceitavam discutir uma reforma agrária depois da revolução socialista ${ }^{28}$. Havia, contudo, aqueles que aceitavam negociar e Antonio Ledesma, deputado junto ao parlamento, levou, em 1964, a proposta de desapropriação sem indenização, sob dois argumentos principais: ou a terra fora tomada às comunidades e, portanto, nada havia que indenizar; ou o camponês trabalhara vários anos gratuitamente como yanacona e também não havia por que falar em indenização ${ }^{29}$.

\footnotetext{
${ }^{27}$ Ver: Contreras, Carlos; Cueto, Marcos (2007). Historia del Peru Contemporaneo: Desde las luchas por la Independencia hasta el Presente, Lima: Instituto de Estudios Peruanos, p. 135.

${ }^{28}$ CCP, março de 1972, p. 21.

${ }^{29}$ Ver: Mar, J. M.; Mejía, J. M. (1980). Op. cit., p. 85.
} 
Evidentemente, a proposta não prosperou no Parlamento. Por causa da repressão, que continuava existindo sobre os grupos de esquerda, que não se comprometiam com a proposta velasquista, mas também por sua postura sectária, os dirigentes da CCP, sob a liderança de Manuel LLamoja Mitmac, Saturnino Paredes e Justiniano Menaya, encontravam-se isolados das bases. Assim, enquanto muitos sindicatos apoiavam a reforma governamental, ou procuravam ocupar terras a fim de tornar a desapropriação das mesmas um fato consumado, os líderes da entidade insistiam em taxar de terratenente e burguesa a reforma agrária e exigir (sem grandes possibilidades naquele momento) uma reforma sem indenização, no qual os camponeses não pagassem pela terra recebida. ${ }^{30}$ Podemos encontrar momentos onde se apoia ocupações, desde que venham com o objetivo do não pagamento pela terra. ${ }^{31}$

Enquanto isso, o governo velasquista busca criar uma confederação oficial para incorporar os beneficiários da reforma agrária, liquidar o que restava das entidades de proprietários e exigir que só sindicatos ligados a essa confederação pudessem negociar com o Estado. Em 1972, o Decreto-lei 19.400 cria a Confederación Nacional Agraria, a fim de que só sindicatos a ela ligados pudessem ser reconhecidos. A resistência de federações como a de Cuzco impediu o objetivo governamental, mas a confederação foi criada em 1974, com seus representantes sendo instalados onde antes funcionara 0 Congresso Nacional.

O governo militar também criara o Sistema Nacional de Apoio à Mobilização Social (Sinamos) em 1971, que buscou angariar respaldo popular ao regime (muito distinto do Brasil, onde a Arena era principalmente uma agremiação eleitoral) tendo como objetivo principal criar sindicatos camponeses atrelados ao Estado. As lutas entre CCP e Sinamistas marcariam os primeiros anos da década de $1970 .^{32}$

Em 1973, uma crise eclode no interior da direção da CCP. O IV Congresso convocado para Ecash, no Departamento de Ancash, é suspenso após desentendimento entre o grupo de Saturnino Paredes e Justiniano Menaya e aqueles liderados por Andrés Luna Vargas e o secretário-geral LLamoja Mitmac. Aparentemente o problema se dava por razões de segurança, pois o grupo de Luna Vargas não se sentia em condições de permanecer no recinto. Entretanto, ao analisar o Informe ao IV Congresso, que se realizou em maio de 1974, em Torre Blanca, Departamento de Uaral, pode-se vislumbrar que o problema do isolamento da entidade em relação às bases tornava-se um incômodo

\footnotetext{
${ }^{30}$ Vale lembrar que, no caso peruano, as indenizações foram pagas com valores calculados a partir do que se pagava em impostos, o que as tornou extremamente baixas. Ver: Mayer, Enrique (2009). Cuentos Feos de la Reforma Agrária, Lima: Instituto de Estudios Peruanos, p. 54.

${ }_{31}$ Ver: "Campesinos no pagarán por la tierra”. Voz Campesina, Novembro de 1972, p. 5.

${ }^{32}$ Ver: Jornal Voz Campesina, Novembro de 1972, p. 8.
} 
para o grupo de Luna Vargas. Basta observar que nas propostas do IV Congresso realizado em Torre Blanca, ainda que se critique a reforma agrária velasquista, pede-se apoio ao Estado para que se estenda o crédito aos novos beneficiários da reforma agrária e medidas como extensão do salário mínimo e aposentadoria. ${ }^{33}$

A partir desse momento, três entidades buscariam reivindicar o nome CCP: o grupo liderado por Andrés Luna Vargas, que procurou apoiar ocupações de terra em Andahuaylas, Departamento de Apurímac (1974), e buscou ampliar suas alianças, participando mais tarde das greves gerais de 1977 e 1978; o grupo de Saturnino Paredes, que continuou aferrado às concepções mais isolacionistas; e o grupo liderado pelo antigo secretário-geral LLamoja Mitimac, que deixou poucos vestígios.

Enquanto, no Peru, o movimento camponês dividia-se e a reforma agrária avançava, no Brasil, a reforma era paralisada, e o movimento sindical crescia. Em 1973, após vários encontros estaduais e regionais, apesar de "recomendações" do ministro do Trabalho para que não se discutissem temas sensíveis como a reforma agrária (Contag, 2004) realiza-se o II Congresso de Trabalhadores Rurais, que manteve a linha legalista, mas tocou nos temas sensíveis. A reforma agrária, os direitos trabalhistas, a previdência, além de um tema muito sensível para os nordestinos, a lei do sítio (dois hectares para o canavieiro cultivar a subsistência nos engenhos). Dentro da lógica de que os direitos existiam, mas não eram respeitados, os dirigentes rurais buscavam fazer destes direitos o referencial para o desenvolvimento da luta. Não é demais lembrar que essa postura moderada não impedia a repressão governamental, mas talvez tenha colaborado para melhor confrontá-la.

Outra reivindicação do II Congresso, e que marcaria a atuação da Contag nos anos 1970, era que a terra fosse distribuída na região de morada do camponês. Isso significava opor-se aos megaprojetos, como a instalação de milhares de gaúchos e nordestinos na Amazônia, às margens de rodovias como a Cuiabá-Santarém e a Transamazônica. ${ }^{34}$ Justamente na Amazônia começa a gestar-se um movimento, que no futuro faria concorrência à Contag. A partir da pregação de padres, como D. Pedro Casaldaglia, questionam-se as incontáveis violações que posseiros vinham sofrendo em estados como Pará, Goiás e Mato Grosso. Essa pregação católica, que se engajava progressivamente

\footnotetext{
${ }^{33}$ As versões sobre o IV Congresso são extremamente contraditórias. Os ligados ao grupo de Paredes chegam a acusar os dirigentes ligados a Vargas como responsáveis pela morte de Justiniano Menaya, assassinado por forças policiais. Ver: Menaya, Gloria A. Justiniano. Voz Campesina, Março de 1976, p. 5. A versão do grupo Luna Vargas e as Propostas do IV Congresso podem ser observadas em: Resoluciones y Conclusiones del IV Congresso de la Confederación Campesina del Peru. Lima, CCP, 1974, pp. 31-43.

${ }_{34}$ Ver: "Segundo Congresso Nacional de Trabalhadores Rurais". Revista O Trabalhador Rural, maio de 1973, p. 20.
} 
no discurso de Teologia da Libertação, vai paulatinamente gestando a Comissão Pastoral da Terra (CPT), que nasce em 1975. Num primeiro momento, pode-se dizer que haveria uma relativa divisão de trabalho: enquanto a Contag atuava mais em áreas como o Nordeste e o Rio Grande do Sul, a CPT atuaria mais fortemente em áreas como o Mato Grosso e Amazônia.

Essa atuação da Igreja era percebida durante o governo Ernesto Geisel como potencialmente desestabilizadora, pelas duras críticas que se fazia não só à atuação ou à falta dela nas áreas de conflito rural, mas também ao próprio modelo de desenvolvimento capitalista, visto como concentrador da renda e da terra. ${ }^{35}$

Enquanto a crise econômica que se desenvolvia forçava o governo Geisel a distender o regime mais do que gostaria e os conflitos no campo se intensificavam com expulsões de posseiros, não apenas na Amazônia, crescimento do êxodo rural e aumento da concentração da terra, Contag e CPT intensificavam sua atuação, multiplicando as denúncias contra a violência no campo e as duras condições de vida no meio agrário.

Também no Peru mudanças importantes ocorriam: doente, enfrentando uma grave crise econômica, o general Velasco foi derrocado por um golpe liderado por seu ministro da Economia, o também general Francisco Morales Bermudes, em 1975. No ano seguinte, aumentam as expropriações e adjudicações de terras, mas, a partir de 1977, a reforma agrária seria paralisada. Os que tinham recebido a terra agora eram cobrados de seu pagamento e não conseguiam crédito nos bancos. As reivindicações da Confederación Campesina/Luna Vargas passavam a ser não tanto a terra, mas as condições para cultivá-la. Necessitavam-se crédito, fertilizantes, inseticidas, transportes, mercados $^{36}$. Mesmo a Confederación Agraria passava a ter uma postura mais crítica em relação ao Estado, agora que os "generais de esquerda" viam-se afastados do regime.

Tanto no Atlântico como no Pacífico, a crise econômica dinamizada a partir da alta dos preços do petróleo, em 1973, e do posterior aumento dos juros nos Estados Unidos tornava necessário para os regimes militares remodelar-se para sobreviver. No Peru, o remédio foi convocar eleições para uma Assembleia Constituinte, em 1978, e presidenciais, para 1980. No Brasil, o regime ainda pôde modernizar-se com a volta dos exilados e um longo processo de transição culminado na assinatura da Constituição Federal de 1988. Contudo, apesar de uma reforma agrária feita com dificuldades no Peru e não realizada no Brasil e do êxodo rural constante, que inchava Rio de Janeiro, São

\footnotetext{
${ }^{35}$ Nos informes do extinto Serviço Nacional de Informações (SNI) a Geisel, a questão agrária é vista como explosiva. Ainda mais que viera do campo, mais exatamente da região do Araguaia, o principal desafio armado ao regime militar, sob a inspiração do PCdoB. Sobre a questão agrária durante o governo Geisel ver, por exemplo: Arquivo EG-04-22-1974-CPDOC-FGV.

${ }^{36}$ Ver: Salgado, C. M. (1989). Op. cit., p. 32.
} 
Paulo e Lima, os movimentos camponeses teriam de ser levados em conta nas conjunturas de transição.

\section{MOVIMENTOS CAMPONESES E A DEMOCRATIZAÇÃO: A QUESTÃO AGRÁRIA NAS TRANSIÇÕES POLÍTICAS}

Quando, em 1979, foi promulgada a nova constituição peruana, a estrutura agrária do país estava bastante alterada em relação a 1969. Nove milhões de hectares tinham sido arrebatados aos proprietários e passados em cooperativas de vários modelos para os trabalhadores. Entretanto, os problemas agora eram de outra natureza: na década que terminava eclodiram conflitos entre técnicos e beneficiários, com os primeiros tentando impor aos últimos o que e como plantar. Houvera uma tentativa de criar cooperativas que englobassem antigas fazendas e comunidades vizinhas, sendo estas beneficiárias daquelas, mas os conflitos continuaram, e, em 1987, cooperativas do Departamento de Puno foram ocupadas por comunidades vizinhas ${ }^{37}$. Como o Estatuto da Terra brasileiro, a legislação peruana havia sido pensada para atender os que trabalhavam nas antigas fazendas e os trabalhadores eventuais continuavam sem terra.

Ao mesmo tempo, as cooperativas careciam de uma administração eficiente e faltavam recursos vindos do Estado, cada vez mais endividado ${ }^{38}$. A década de 1980 veria novas dificuldades para o setor reformado. O crédito escasso nos últimos anos do governo militar desapareceria sob o novamente eleito Fernando Belaunde. As secas e inundações causadas pelo fenômeno El Niño, que também afetaram o Brasil em 1983, atingiam duramente áreas como Puno. A resposta da CCP foi tentar unir-se à CNA criando a Frente Unida para o Desenvolvimento Agrário, em 1981, além de protestar contra a nova Lei de Desenvolvimento Agrário, que permitia amplíssimas concessões de terras na Amazônia. ${ }^{39}$

Outro problema tornaria mais difícil a atuação da CCP: a emergência do Sendero Luminoso, pois essa organização escolhera o campo como lugar para seus ataques iniciais. Não seriam líderes oligárquicos seus principais alvos, mas dirigentes de organizações de esquerda, que não aceitassem sua proposta de construção de uma república popular moda maoísta no Peru.

\footnotetext{
${ }^{37}$ Ver Rénique, José Luiz (2004). La Batalla por Puno: Conflicto y Nación en los Andes Peruanos, Lima: Cepes-Sur, p. 227.

${ }^{38}$ Ver Burenius, Charlot (2001). Testemuño de un Fracaso: Habla El Sindicalista Zózimo Torres, Lima: Desco, p. 143.

${ }_{39}$ Ver Voz Campesina, Fevereiro de 1981. p. 8. Ver também: Vargas, Andrés Luna (1981). La CCP frente a la ley de promoción y desarrollo agrario, Lima: CCP, p. 14.
} 
Assim, a segurança passa a ser uma reivindicação nos congressos da CCP de 1982 e 1987, pois o dirigente camponês encontrava-se literalmente entre dois fogos: as ações do exército e dos paramilitares e as do Sendero Luminoso ${ }^{40}$. Assim a representação da CCP ia diluindo-se durante a década de 1980, culminando num violento refluxo após a implementação das políticas neoliberais de Alberto Fugimori a partir de sua eleição, em 1990.

No Brasil, durante o ano de 1979, que marcaria a volta dos exilados e as greves dos metalúrgicos no $A B C$ paulista, de onde emergiria a figura do futuro presidente Luiz Inácio Lula da Silva, a Contag realiza seu III Congresso, para não mais pedir e sim exigir o cumprimento do Estatuto da Terra e a realização da reforma agrária. Nos primeiros anos da década de 1980, a entidade busca uma unidade com a Central Única dos Trabalhadores (CUT), mas a emergência do Movimento dos Trabalhadores Rurais Sem Terra (MST) leva a uma competição pela representação dos trabalhadores do campo. Para os sem-terra o "legalismo" da Contag limitava a luta, embora tenha sido aplicando estes marcos legais que a Contag levou a efeito bem-sucedidas greves em Pernambuco, em 1979, e no Rio de Janeiro, em 1984.

A Contag engajou-se no apoio a candidatos nas eleições de 1982, nas campanhas pelas eleições diretas para presidente, em 1984, e na eleição de Tancredo Neves. Com o governo Sarney, que anunciava o Plano Nacional de Reforma Agrária, os dirigentes da Contag vislumbraram a possibilidade de ver finalmente o Estatuto da Terra aplicado. Mas a reação dos proprietários não tardaria. Um mês após o anúncio do Plano de Reforma Agrária, era lançada, em junho de 1985, a União Democrática Ruralista (UDR). Multiplicaram-se rapidamente as acusações de assassinatos de padres, advogados e líderes de trabalhadores rurais num contexto em que o MST dinamizava as ocupações de terra no Rio Grande do Sul e cresciam os conflitos na região conhecida como Bico-doPapagaio (divisa de Tocantins, Maranhão e Pará).

Rapidamente, o plano é descaracterizado e a Contag aposta suas fichas na Assembleia Constituinte. Na assembleia, o setor proprietário largou na frente, posto que na milionária campanha de 1986 elegeu dezenas de representantes no Congresso Nacional. Enquanto o governo Sarney revogava, em 1987, princípios do Estatuto da Terra $^{41}$, a Contag os via derrubados também na Constituinte. Antes, o argumento era de que era melhor avançar a agricultura tecnicamente e, então, ela já estava avançada. A

\footnotetext{
${ }^{40}$ Ver Rénique, J. L. (2004). Op. cit., p. 215; Salgado, C. M. (1989). Op. cit., p. 37.

${ }^{41}$ Declarava-se o fim do módulo fiscal e extinguia-se o Instituto Nacional de Colonização e Reforma Agrária (Incra) com o Decreto-lei 2363-87. Ver Ricci, Rudá (1990). Contag: Um ator à procura de um texto. São Paulo: Cadernos CEDEC. p. 66 . O Incra seria recriado pelo Decreto Legislativo 2/89.
} 
reforma agrária aqui era condicionada ao princípio da propriedade produtiva, o que abria ampla margem de manobra ao setor proprietário. O módulo fiscal do Estatuto da Terra, que tinha aberto a possibilidade de haver uma área máxima no país a partir da qual se desapropriaria, ficava cancelado.

Enfrentando a competição do MST, a Contag veria sua luta por reforma agrária perdida, porque a lei, pelo menos naquele momento, se voltava contra ela. O MST continuaria com as ocupações. Tanto a Contag quanto a CCP teriam nos anos 1990 de enfrentar as medidas liberalizantes de Fernando Collor e Alberto Fugimori, respectivamente. A luta por reformas que as entidades, de acordo com cada contexto, haviam encarnado parecia encerrada. Parecia, mas não estava.

\section{CONCLUSÃO}

Como afirmamos no início deste trabalho, comparar é tão perigoso quanto necessário. Encontramos aqui pontos de convergência nas histórias brasileira e peruana. Ambos os países passaram por regimes militares (a tradição de intervenção militar na vida peruana é muito maior que na brasileira) e por processos de urbanização acelerados de modernização de suas estruturas sociais. Contudo, as diferenças também são importantíssimas: o Peru tem um forte contingente populacional indígena e, mais do que isso, tem ainda comunidades indígenas, que jogam um papel fundamental no desenvolvimento do país.

O problema agrário foi percebido pelas duas burocracias militares como explosivo. No Brasil, um setor minoritário da oficialidade entendia que era indispensável garantir a terra ao camponês, tanto para ampliar mercado para a indústria quanto para evitar conflitos. No Peru, havia os mesmos objetivos, mas ali se entendia, desde a ascensão dos militares, que o Estado teria de ter participação substantiva no processo de industrialização. Só um país industrializado poderia evitar os inimigos externos (o Brasil poderia ter sido um deles) e combater os levantes internos. Mais ainda: era preciso incorporar o índio, potencialmente rebelde aos desígnios de Lima.

Talvez por isso a reforma agrária tenha sido realizada, com todas as limitações, no Peru, e, no caso brasileiro, onde a indústria já se desenvolvera podendo contar com o mercado urbano, além de se poder acenar ao camponês com o eterno deslocamento para novas fronteiras (neste caso, a Amazônia), tenha sido possível modernizar o país, conservando sua estrutura fundiária. 
Nestes contextos, a recém-criada Contag e a CCP teriam de atuar. Aqui buscou-se a todo custo evitar o confronto, face à dura repressão dos primeiros tempos. Nos anos 1980, dirigentes da Contag seriam acusados de excessivamente moderados, mas nos anos 1970, sua prática garantia a sobrevivência do movimento sindical, mantendo alçada a bandeira da reforma agrária.

A CCP isolou-se das bases enquanto sua congênere brasileira tentava ampliar a sua. Os dirigentes da CCP desqualificaram imediatamente a reforma velasquista. Hoje, Jorge Prado, o secretário-geral, reconhece a importância da reforma, mas ao lermos a Voz Campesina ou os informes ao III Congresso, vemos sua desqualificação. A partir da crise de 1973, o grupo de Luna Vargas aproxima-se de outros setores e participa das greves gerais, das lutas na Assembleia Constituinte e na organização de uma frente de esquerda, que lançou Hugo Blanco à presidência em 1980.

A década de 1980, marcada por elevadíssima inflação nos dois países, encontra a Contag em fase de expansão e vivendo uma experiência que, no Peru, só por breve tempo a Confederación Nacional Agraria viveria: apoiar o governo Sarney. Já a CCP muda $o$ tom das reivindicações, que agora eram menos a terra e mais as condições de vida.

Nos anos 1990, as duas entidades enfrentam as medidas neoliberais. Com Alberto Fugimori o Peru vê o Estado retraindo-se e não mais apoiando a agricultura. No Brasil, Collor liquida o esquema do governo Federal de apoio a pequenos agricultores. Atualmente, as duas entidades levantam as bandeiras ecológicas do crescimento sustentável e do combate aos transgênicos. A Contag ainda sustenta a reforma agrária. Já a CCP luta contra as concessões de terras a grandes grupos internacionais.

Embora a presença dos partidos comunistas e de outras organizações tenha sido fundamental para o nascimento dessas entidades, isso não desqualificou suas lutas, na medida em que em ambos os casos buscou-se um diálogo com o campesinato, a fim de tentar preencher suas necessidades. É certo que no caso da CCP houve um distanciamento das bases, mas isso não significou que não pudesse haver a reaproximação. As duas casas são referências obrigatórias para pensar o movimento camponês e seus países, mesmo numa perspectiva latino-americana.

\section{REFERÊNCIAS BIBLIOGRÁFICAS}

Ayved, Bernardete (1982). A Vitória dos Vencidos. Dissertação de Mestrado, UFPB, Campina Grande. 
Barcelos Fernando (2008). Sindicalismo e Luta pela Terra no Rio de Janeiro. Dissertação de Mestrado, Centro de Pós-Graduação em Desenvolvimento Agrário, Rio de Janeiro.

Bassani, Paulo (2009). Frente Agrária Gaúcha e Sindicalismo de Trabalhadores Rurais, Londrina: EDUEL.

Burenius, Charlot (2001). Testemuño de un Fracaso: Habla el sindicalista Zózimo Torres, Lima: Desco.

Castro, Celso (1995). Visões do Golpe. Memória Militar sobre 1964, Rio de Janeiro: Fundação Getúlio Vargas. [V.I].

Colombo, Silvia; Soares, Gabriela Pelegrino (1999). Reforma Liberal e Lutas Camponesas na América Latina: Peru e México nas últimas décadas do século XIX e princípios do século XX, SP: Humanitas.

Contreras, Carlos; Cueto, Marcos (2007). Historia del Peru Contemporaneo: Desde las luchas por la Independencia hasta el Presente, Lima: Instituto de Estudios Peruanos.

Cotler, Julio (2006). Peru: Estado, Classe e Nação, Brasília: Fundação Alexandre Gusmão, 2006.

Dreifus, René Armand (1981). 1964: A Conquista do Estado, Petrópolis: Vozes.

Iokoi, Zilda Márcia Gricoli (1996). Igreja e Camponeses: Teologia da Libertação e Movimentos Sociais no Campo (Brasil e Peru: 1964-1986), São Paulo: Hucitec.

Lenharo, Alcir (1986). Trabalho e Colonização no Brasil: Nordeste, Amazônia CentroOeste, Campinas: Papirus.

Mar, José Matos; Mejía, José Manuel (1980). La Reforma Agraria en el Peru, Lima: Instituto de Estudios Peruanos.

Martins, José de Souza (1984). A Militarização da Questão Agrária, Petrópolis: Vozes. 
Mayer, Enrique (2009). Cuentos Feos de la Reforma Agraria, Lima: Instituto de Estudios Peruanos.

Medeiros, Leonilde Sérvulo (1989). História dos Movimentos Sociais no Campo, Rio de Janeiro: Fase.

Medrano, Eduardo Toche (2008). Guerra Y Democracia. Los Militares Peruanos y la construción nacional, Lima: Desço-clacso.

Moura, Clovis (1983). Sociologia Política da Guerra de Canudos, São Paulo: Hucitec.

Otero, Luis Gamarra (2008). "Un Testemuño Personal”. In: Vegas de Cáceres, lleana (2008). A 38 Años de La Reforma Agraria. Lima: Fund. Manuel J. Bustamante de La Fuente.

Ramos, Carolina (2006). Sindicato Patronal Rural e Reforma Agrária no Brasil: uma análise da atuação da Confederação Nacional de Agricultura frente às políticas governamentais voltadas para a questão fundiária (1961-1970). Dissertação de Mestrado, UFF, Niterói.

Rénique, José Luiz (2004). La Batalla por Puno: Conflicto y Nación en los Andes Peruanos, Lima: Cepes-Sur.

Ribeiro, Vanderlei Vazelesk (2008). Cuestiones Agrárias en el Varguismo y el Peronismo. Quilmes: Universidad Nacional de Quilmes.

Ricci, Rudá (1990). Contag: Um ator à procura de um texto, São Paulo: Cadernos CEDEC.

Salgado, Carlos Monge (1989). Agremiación en el campo peruano. La Historia de La Confederación Campesina, Lima: Latino-American Studies Association.

Salis, Carmem Lucia Gomes de (2008). Estatuto da Terra: Origem e (Des)caminhos da Proposta de Reforma Agrária nos Governos Militares. Tese de Doutorado, UNESP, Assis. 
Silva, José Gomes da (1971). A Reforma Agrária no Brasil: Frustração Camponesa ou Instrumento de Desenvolvimento? Rio de Janeiro: Zahar.

Tavares, Ricardo (1992). CONTAG: Da Ditadura à Transição. Memória Social e Construção Política do Campesinato. Dissertação de Mestrado, IUPERJ, Rio de Janeiro.

Vargas, Andrés Luna (1981). La CCP frente a la ley de Promoción y desarrollo agrario, Lima: CCP.

Recebido para publicação em agosto de 2010. 